\title{
Pulmonary hypertension: its assessment and treatment
}

\author{
Seema Brij, Andrew J Peacock \\ Scottish Pulmonary Vascular Unit, Western Infirmary, Glasgow, UK
}

Introductory articles

\section{Inhaled nitric oxide as a screening agent for safely identifying responders to oral calcium-channel blockers in primary pulmonary hypertension}

O Sitbon, M Humbert, J-L Jagot, O Taravella, M Fartoukh, F Parent, P Herve, G Simonneau

In a subset of patients with primary pulmonary hypertension (PPH), high doses of oral calcium-channel $\stackrel{\circ}{2}$ blockers (CCB) produce a sustained clinical and haemodynamic improvement. However, significant side- $\vec{\longrightarrow}$ effects have been reported during acute testing with CCB. Therefore, to identify accurately patients

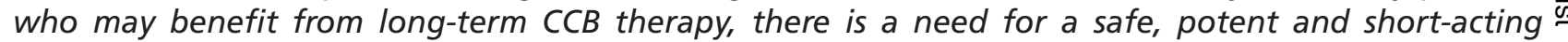
vasodilator. The aim of this study was to compare the acute response to inhaled nitric oxide (NO) and $\vec{\oplus}$ oral high doses of CCB in 33 consecutive patients with PPH. A significant acute vasodilator response was defined by a fall in both mean pulmonary artery pressure and total pulmonary resistance by $>20 \%$. Ten patients responded acutely to NO, nine of whom responded acutely to CCB, without any complications. The 23 other patients failed to respond to NO and CCB. In these non-responders, nine serious adverse events were observed with CCB (38\%). There was no clinical or baseline haemodynamic $\stackrel{\otimes}{\mathbb{Q}}$ feature predicting acute vasodilator response. Long-term oral treatment with CCB was restricted to the $\overrightarrow{\overrightarrow{0}}$ nine acute responders and a sustained clinical and haemodynamic improvement was observed in only $\Xi$ six patients. In primary pulmonary hypertension, the acute response rate to high doses of calciumchannel blockers is low (27\%). Serious adverse reactions to high doses of calcium-channel blockers during acute testing are frequently observed in non-responders. It is concluded that nitric oxide may be used as a screening agent for safely identifying patients with primary pulmonary hypertension who ? respond acutely to calcium-channel blockers and may benefit from long-term treatment with these agents. (Eur Respir J 1998;12:265-70)

\section{Reduction in pulmonary vascular resistance with long-term epoprostenol (prostacyclin) therapy in primary pulmonary hypertension}

\author{
V V McLaughlin, D E Genthner, M M Panella, S Rich
}

Background. Primary (idiopathic) pulmonary hypertension is a progressive, fatal disease. Conventional $\underset{0}{\mathrm{O}}$ therapy with anticoagulant and vasodilator drugs may improve symptoms and survival among selected patients, but there is no evidence that the disease can be reversed. Methods. We evaluated the effects $\mathbb{\varnothing}$ of long-term therapy (i.e., for more than one year) with intravenous epoprostenol (prostacyclin) in $\stackrel{+}{+}$ patients with advanced primary pulmonary hypertension. The base-line evaluation included an 0

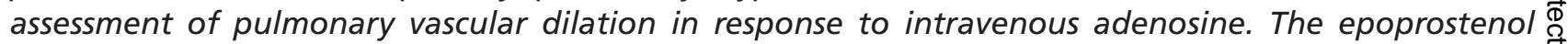
dose was increased monthly to the maximum tolerated. Long-term therapy was evaluated by measuring $\stackrel{\mathbb{\Omega}}{\Omega}$ improvement in symptoms, exercise capacity, and hemodynamic variables. Results. We evaluated 27 ? patients with primary pulmonary hypertension over a mean ( $\pm S D$ ) period of $16.7 \pm 5.2$ months. 8 Intravenous adenosine had a variable effect on pulmonary vascular resistance (mean reduction, $27 \leqq$ percent; range, 0 to 56; $P<0.001)$. Epoprostenol therapy was initiated and the rate of infusion was $\frac{\overline{0}}{\Rightarrow}$ increased by an average of $2.4 \mathrm{ng}$ per kilogram of body weight per minute each month. Twenty-six of the 27 patients had improvement in symptoms and hemodynamic measures, and overall, pulmonary vascular resistance declined by 53 percent to $7.8 \pm 3.8$ resistance units $(P<0.001)$ at the time of re-study. The long-term effects of epoprostenol exceeded the short-term pulmonary vasodilator response to adenosine in all but one patient. Seven of the eight patients who had minimal pulmonary vasodilation 
in response to adenosine (mean reduction in resistance units, $<20$ percent) still had a significant reduction in pulmonary vascular resistance when treated with epoprostenol (mean, 39 \pm 14 percent; $P<0.002)$. Conclusions. In primary pulmonary hypertension, long-term therapy with epoprostenol lowers pulmonary vascular resistance beyond the level achieved in the short term with intravenous adenosine. Epoprostenol appears to have sustained efficacy in this disorder. (N Engl J Med 1998;338:273-7)

Primary pulmonary hypertension $(\mathrm{PPH})$ is a rare and fatal condition characterised by raised pulmonary artery pressures and increased pulmonary vascular resistance. The estimated annual incidence is $1-2$ cases per million people per year 1 The aetiology is unknown. Although this disease can occur at any age, it generally affects a younger population with the mean age at diagnosis being 36 years. ${ }^{2}$ Women are affected more commonly than men. The median survival from time of diagnosis is $2-3$ years with a five year survival of less than $40 \%$

Until recently treatments for this devastating illness have concentrated on high dose calcium channel blockers, warfarin, oxygen, and transplantation. High dose calcium channel blockers improve symptoms and survival in a well defined population which can currently only be identified at right heart catheterisation. Treatment with continuous intravenous prostacyclin and its analogues is in its infancy but the initial results are very favourable with continuing haemodynamic improvement at $2-3$ years.

Two publications in 1998 may change the way we assess and treat pulmonary hypertension.5 The current practice in pulmonary vascular units is to assess the vasodilator response of the pulmonary circulation and initiate therapy. Sitbon et al presented a novel evaluation technique using inhaled nitric oxide to identify pulmonary vasodilator "responders" 4 McLaughlin et al have shown that prostacyclin provides benefit over calcium channel blockers when used as long term therapy.

\section{Acute vasodilator studies: looking for "responders"}

Calcium channel blockers have stood up to scrutiny in the last 10 years in the treatment of pulmonary hypertension. Using higher doses than those used to treat systemic hypertension, it has been shown that there is continued haemodynamic improvement at one year in "responders", a population in whom there had been a demonstrable immediate decrease in the mean pulmonary artery pressure (mPAP) and an increase in the cardiac output (CO) 6 These acute haemodynamic responses occur in only one third of patients with $\mathrm{PPH}$. It is thought that acute vasodilatation may indicate the additional presence of active vasoconstriction as well as obstruction to flow secondary to remodelling in the vascular wall

Rich and Brundag $£^{6}$ produced guidelines for the assessment of acute vasodilator status which have now been accepted as the gold standard. To distinguish "responders" from "non-responders" involves the positioning of a thermodilution catheter in a proximal lobar pulmonary artery. Baseline pressure studies and estimation of cardiac output are performed, allowing pulmonary vascular resistance (PVR) or total pulmonary resistance (TPR) to be calculated. The patient is then transferred to a high dependency unit with the catheter in situ and challenged with oral calcium channel blockers. The administration of calcium channel blockers is repeated (nifedipine $20 \mathrm{mg}$ or diltiazem $60 \mathrm{mg}$ ) on an hourly basis up to eight times until there is either a $\frac{\overline{\bar{m}}}{\bar{D}}$ $>20 \%$ reduction in both $\mathrm{mPAP}$ and PVR/TPR or the $\stackrel{\mathbb{Q}}{\Omega}$ patient becomes symptomatic. This is a positive vasodilator study and the patient is a "responder". If there $\overrightarrow{0}$ is no change in mPAP, PVR or TPR, a failure to tolerate the side effects of oral calcium channel blockers, or $\vec{\omega}$ hypotension or bradycardia, the patient is classified as a "non-responder".

Acute vasodilator studies identify individuals in whom $\stackrel{\leftrightarrow}{\perp}$ treatment with long term high dose calcium channel 0 blockers is appropriate. Half of the cumulative drug $\varnothing_{\infty}$ dose that produces a response can be administered 6-8 is hourly on a regular basis.

\section{Acute vasodilator study agents}

Even to the uninitiated, the above regime seems un- क् workable when high dependency bed space is at a $\vec{\bullet}$ premium. A more rapid system of assessment is peeded. $\mathbb{E}$

Nebulised prostacyclin 7 and nitric oxide NO 10 and intravenous prostacyclin 11 and adenosin $\AA^{12}$ have been used as agents in acute vasodilator studies. They are titratable, show rapid activity, have short half lives and, in the case of inhaled NO which is inactivated before $\frac{\circ}{\mathbb{D}}$ reaching the systemic circulation, are selective to the pulmonary circulation. More importantly, the haemodynamic data are available within minutes rather than hours.

\section{PROSTACYCLIN}

Prostacyclin is produced by the vascular endothelium. It is a potent short acting vasodilator and inhibitor of $\dot{\delta}$ platelet aggregation which produces its vascular effects by increasing cyclic AMP in smooth muscle cells. The $\mathrm{o}$ half life is short ( 3 minutes). It can be administered via a peripheral vein for acute vasodilator studies.

Acute vasodilator testing with intravenous prostacyclin is accomplished using a peripheral infusion. The $\Omega$ starting dose is $1-2.5 \mathrm{ng} / \mathrm{kg} / \mathrm{min} 1 \mathrm{1}$ and is increased every $\mathrm{N}$ 10 minutes by $1-2.5 \mathrm{ng} / \mathrm{kg} / \mathrm{min}$ to a maximum dose of $N$ $10 \mathrm{ng} / \mathrm{kg} / \mathrm{min}$ until there is either a reduction in mPAP $\underset{2}{ }$ and PVR, the side effects are intolerable, or there is no response. Prostacyclin reduces PVR and increases CO $\mathbb{D}$ when administered acutely to patients with $\mathrm{PPH}{ }^{11}$ It $\stackrel{+}{+}$ may also produce an unwanted decrease in the systemic $\frac{0}{0}$ vascular resistance and systolic blood pressure. ${ }^{14}$ The patient may experience chest pain, flushing sensations, jaw pain, headache, and diarrhoea.

Acute vasodilator testing with inhaled prostacyclin is achieved by nebulising $2 \mathrm{ml}$ prostacyclin solution of $\frac{0}{0}$ known concentration $(15-5 \mathrm{ng} / \mathrm{kg} / \mathrm{min})$ in eight litres of oxygen for 20 minutes "Responders" are rated 흘 as previously. Nebulised prostacyclin produces greater decreases in mPAP and PVR than intravenous prostacyclin, although these data have not been corrected for equivalent drug dosing. Mikhail et al found that the haemodynamic effects of prostacyclin were temporary and reversed after 10 minutes. There were no side 
effects reported with nebulised therapy and there was no significant effect on systemic arterial pressure.

\section{ADENOSINE}

Adenosine is a naturally occurring purine nucleoside and an intermediate product of adenosine trisphosphate (ATP) metabolism. It has been shown to cause relaxation of human pulmonary arterie 16 but also reduces systemic vascular resistance (SVR) HIt is more commonly used in the termination of junctional tachycardias and to block atrioventricular conduction. It has a very short half life (13 seconds). The side effects are short lived but include chest pain and bronchospasm, so adenosine should not be given to asthmatic subjects. In our unit we currently use peripheral venous infusions of adenosine to assess "responder" status in the cardiac catheter suite. ${ }^{18}$ After initial baseline studies we administer adenosine at $50 \mu \mathrm{g} / \mathrm{kg} / \mathrm{min}$ and increase the rate by $50 \mu \mathrm{g} / \mathrm{kg} / \mathrm{min}$ every two minutes until the patient experiences symptoms such as wheezing or chest pain or there is a positive cardiovascular response. If there is no response the infusion is stopped at $350 \mu \mathrm{g} / \mathrm{kg} / \mathrm{min}$. In an audit of 72 patients we have experienced no serious haemodynamic collapse following adenosine infusions (1998 Pulmonary Vascular Unit Audit, unpublished observation) However, patients with PPH are haemodynamically very brittle and there is always concern regarding systemic hypotension.

\section{NITRIC OXIDE}

Nitric oxide (NO) is produced in the normal pulmonary artery by the enzyme nitric oxide synthase (NOS) in endothelial cells. NO diffuses into underlying vascular smooth muscle cells and binds to soluble guanylate cyclase, thus stimulating the production of cyclic 3,5monophosphate (cGMP) which results in smooth muscle relaxation $1{ }^{20}$

$\mathrm{NO}$ is commercially available in cylinders as pure $\mathrm{NO}$ and as an $\mathrm{NO} / \mathrm{N}_{2}$ mix. The desired concentration is controlled using chemiluminescence and administered with air via a face mask. Sitbon et al have previously shown that inhaled $\mathrm{NO}$ at $10 \mathrm{ppm}$ over six minutes was equivalent to intravenous prostacyclin $(10 \mathrm{ng} / \mathrm{kg} / \mathrm{min})$ in reducing mPAP and PVR in "responders". In the current pape they show that NO is safer than calcium channel blockers for use in acute vasodilator studies in a population of 33 patients with severe PPH. They performed acute vasodilator studies first using inhaled $\mathrm{NO}$ at $10 \mathrm{ppm}$ for 6-10 minutes and then followed the Rich and Brundage guideline for testing using oral calcium channel blockers. Subjects in whom there was a reduction in MPAP and PVR were regarded as "responders". The "responders" were then given optimum doses of oral calcium channel blockers and re-catheterised at a later date.

The results showed that "responder" status (33\%) could be identified using inhaled NO. All those who showed a response with calcium channel blockers responded to NO $(n=9)$. One patient did not respond to high dose calcium channel blockers but did respond to NO. The "responders" had a bigger response to NO than to oral calcium channel blockers. The nine "responders" went on to receive oral high dose long term calcium channel blockers. Six patients had sustained haemodynamic improvement, two failed to respond to long term treatment and there was one death.

Adverse effects were experienced with oral acute calcium channel blockers but not with inhalation of
NO. Other studies have also shown NO to be safe13 and it is a commonly used study agent in the United States. ${ }^{21}$ The use of calcium channel blockers in PPH is associated with considerable morbidity $22^{23}$ Many of the side effects experienced such as headache, nausea, 응 vomiting and abdominal pain are not life threatening. $\times$ Fatalities, independent of the test agent used, can be $\overrightarrow{\vec{\rho}}$ reduced by excluding patients who have high right atrial $\stackrel{0}{\circ}$ pressures from acute vasodilator testing. ${ }^{24}$ However, fatal outcomes are rare $(<1 \%) 21$

Acute oral calcium channel blocker challenge is an unwieldy tool with which to identify "responders" and there are now alternatives available. Intravenous prostacyclin, intravenous adenosine, nebulised prostacyclin, or $\vec{\circ}$ inhaled NO can all be used to vasodilate the pulmonary $\overrightarrow{\vec{\omega}}$ circulation and predict acute "responder" status. Of $\stackrel{\omega}{\omega}$ these, NO is likely to be the drug of choice because its $\overrightarrow{\vec{x}}$ effects on the systemic circulation are short lived and of not severe.

\section{Long term therapy in PPH}

Until recently the medical treatment for pulmonary hypertension has been limited to warfarin, oxygen, and high dose calcium channel blockers for "responders" in association with diuretics and digoxin as required. Anticgagulation with warfarin appears to prolong sur- $\frac{5}{\infty}$ viva $1^{2}$ and this has been attributed to the reduced risk $\overrightarrow{\vec{\theta}}$ of intravascular thrombosis. Oxygen is only useful if the patient is hypoxaemic at rest and the criteria for domiciliary oxygen in PPH are the same as for chronic obstructive pulmonary disease (COPD).2127 Diuretics may be useful for the oedema associated with right heart $\overline{0}$ failure and with the use of high dose calcium channel blockers.

Intravenous prostacyclin has been used in PPH for $\overrightarrow{\overrightarrow{0}}$ more than 15 years. Due to its short lived effects in the 3 pulmonary circulation prostacyclin needs to be administered continually through an indwelling central venous catheter. Long term therapy with continuous $\overrightarrow{\overrightarrow{0}}$ intravenous prostacyclin via a Hickman line is the most $\frac{0}{2}$ effective treatment for patients with PPH who are unresponsive to oral calcium channel blockers ${ }^{28}$ Patients treated show improved quality of life scores and exercise capacity. 14

Prostacyclin can be nebulised and in Japan an oral 을 prostacyclin analogue, Beraprost, is currently being assessed for long term use. Prostacyclin has also been used as an antiplatelet agent in extracorporeal circulation dialysis and as a digital arteriolar vasodilator $\sigma$ in the treatment of severe Raynaud's phenomenon ${ }^{29}$

McLaughlin et al have now shown that continuous prostacyclin infusion delays the need for transplantation and also reduces PVR in the long term 5 In their series 0 of 27 patients with $\mathrm{PPH}$ they evaluated the acute response to adenosine. All patients were treated with $\stackrel{?}{+}$ intravenous prostacyclin via a Hickman line in- $\frac{0}{0}$ dependent of their "responder" status. The patients were taught how to administer the drug themselves at $\frac{?}{\mathbb{P}}$ home. The dose of drug was increased by $2.4 \mathrm{ng} / \mathrm{kg} / \mathrm{min} \frac{\varrho}{\sigma}$ each month until intolerance developed. The population studied had severe symptomatology and were in NYHA $\delta$ class III or IV at the start of the study. The baseline mPAP was $67 \mathrm{~mm} \mathrm{Hg}$ and the mean duration of tread- $\frac{0}{2}$ mill exercise was 261 seconds. Adenosine reduced the average PVR by $27 \%$ at a mean dose of $211 \mu \mathrm{g} / \mathrm{kg} /$ min. There were eight (30\%) definite "non-responders" (reduction in PVR $<20 \%$ ). The response to adenosine at the baseline catheterisation is not documented as percentage "responders". 


\section{LEARNING POINTS}

\section{* Inhaled nitric oxide can be used acutely to predict long term response to vasodilator therapy in PPH.}

* Continuous long term intravenous prostacyclin improves exercise tolerance even in patients with no acute response to a vasodilator.

The patients underwent repeat cardiac catheterisation 12-24 months later (mean 16.5) and were stratified according to their adenosine response and their use of calcium channel blockers. The results were impressive. In all but one patient there was a greater than $20 \%$ reduction in PVR. Those patients who responded to adenosine had a greater fall in mPAP and PVR than the "non-responders" after long term intravenous prostacyclin therapy but even "non-responders" had significant haemodynamic improvement long term. Patients maintained on oral calcium channel blockers prior to prostacyclin therapy derived the same benefit from additional vasodilatation long term. All patients had a subjective and objective improvement in their symptoms. Their functional NYHA class improved such that $96 \%$ of the study population were graded as NYHA class I or II. The exercise capacity of the study population more than doubled (mean 631 seconds).

Side effects of long term intravenous prostacyclin were common and included diarrhoea, jaw pain, headaches, and flushing. Hickman line infections were mainly confined to the exit site but there were also systemic infections.

McLaughlin et al concluded that prostacyclin caused substantial reductions in PVR in the long term in patients with PPH. These reductions were in excess of those achieved with adenosine in a baseline acute vasodilator study. They conceded that there are problems with dosing prostacyclin as it is currently unclear when maximum benefit can be derived.

The implications of this paper are enormous. Previously, prostacyclin has been reserved for patients in whom there is no response at the acute vasodilator study or in whom there has been no improvement following long term treatment with oral calcium channel blockers. When compared with conventional treatment prostacyclin improved symptoms and haemodynamics in a 12 week period. ${ }^{2}$ The only other treatments for primary pulmonary hypertension were thought to be surgical that is, a single lun $\$^{30}$ or heart-lung transplantatio ${ }^{31}$ and blade balloon atrial septostomy. ${ }^{32}$ Now McLaughlin et al have shown that all patients derive benefits long term from intravenous prostacyclin. However, we must practise caution. We have yet to see a double blind, placebo controlled large trial using long term prostacyclin or one of its analogues in $\mathrm{PPH}$.

Prostacyclin is expensive. The estimated cost of treating PPH with prostacyclin (Flolan) for one year is $£ 4500033$ Currently, there are no definite guidelines for dosing and in McLaughlin's series the highest dose tolerated was used (mean $40 \mathrm{ng} / \mathrm{kg} / \mathrm{min}$ ). The investigators themselves describe their approach to dosing as aggressive. There is little evidence to suggest that tolerance develops, although the highest dose reported is $270 \mathrm{ng} / \mathrm{kg} / \mathrm{min}{ }^{21}$ Can we afford to increase the dose indefinitely?

Further research into this class of medication is required. We need to know if these drugs can be administered on a long term basis via a more convenient route. UT-15, a prostacyclin analogue which can be administered subcutaneously, is currently the subject of $\frac{\vec{\sigma}}{\vec{\phi}}$ a double blind, randomised, placebo controlled, multicentre trial involving over 100 patients in the treatment क arm. There have been anecdotal cases of successful long $\vec{\circ}$ term treatment with nebulised iloprost $(100 \mu \mathrm{g}$ daily in $\vec{\overrightarrow{ }}$ five aerosols ${ }^{34}$ and this may merit evaluation in the $\stackrel{\sigma}{\sigma}$ future.

The field of pulmonary vascular medicine is in its infancy and PPH is a rare disorder, but in the last decade there has been increasing interest in the mysteries $\triangle$ of the abnormal pulmonary circulation. It is evident $\infty$ that there is more research to be done if we are to $N$ improve further the life expectancy of a severely in- $\infty$ capacitated young population who have this fatal disease of unknown aetiology.

1 McDonnell P, Toye P, Hutchins G. Primary pulmonary hypertension and cirrhosis: are they related? Am Rev Respir Dis 1983;127:437-41.

2 Rich S, Dantzker DR, Ayres SM. Primary pulmonary hypertension: a national prospective study. Ann Intern Med 1987;107:216-23.

3 Petitpretz P, Brenot F, Azarian R. Pulmonary hypertension in patients with human immunodeficiency virus infection: comparison with primary pulmonary hypertension. Circulation 1994;89:2722-7.

4 Sitbon $\mathrm{O}$, Humbert $\mathrm{M}$, Jagot J, et al. Inhaled nitric oxide as a screening agent for safely identifying responders to oral calcium-channel blockers in primary pulmonary hypertension. Eur Respir ₹ 1998;12:265-70.

5 McLaughlin VV, Genthner DE, Panella MM, et al. Reduction in pulmonary vascular resistance with long-term epoprostenol (prostacyclin) monary vascular resistance with long-term epoprostenol (prostacyclin)
therapy in primary pulmonary hypertension. N Engl f Med 1998;338: 273-7.

6 Rich S, Brundage BH. High-dose calcium channel-blocking therapy for primary pulmonary hypertension: evidence for long-term reduction in pulmonary arterial pressure and regression of right ventricular hypertrophy. Circulation 1987;76:135-41

7 Zobel G, Dacar D, Rodl S, et al. Inhaled nitric oxide versus inhaled prostacyclin and intravenous versus inhaled prostacyclin in acute respiratory failure with pulmonary hypertension in piglets. Pediatr Res 1995;38:198-204.

8 Pepke-Zaba J, Higgenbottam TW, Dinh-Xuan AT, et al. Inhaled nitric oxide as a cause of selective pulmonary vasodilatation in pulmonary

9 Sitbon O, Brenot F, Denjean A. Inhaled nitric oxide as a screening vasodilator agent in primary pulmonary hypertension: a dose-response study and comparison with prostacyclin. Am $\mathcal{F}$ Respir Crit Care Med $1995 ; 151: 384-9$.

10 Walmrath D, Schermuly R, Pilch J, et al. Effects of inhaled versus intravenous vasodilators in experimental pulmonary hypertension. Eur Respir f 1997;10:1084-92.

11 Rubin LJ, Groves BM, Reeves JT, et al. Prostacyclin-induced acute pulmonary vasodilation in primary pulmonary hypertension. Cir- o culation 1983;66:334-8

12 Morgan JM, McCormack DG, Griffiths MJD, et al. Adenosine as a N vasodilator in primary pulmonary hypertension. Circulation 1991;84: స్ట
$1145-9$.

13 Jolliet $\mathrm{P}$, Bulpa $\mathrm{P}$, Thorens $\mathrm{J}$, et al. Nitric oxide and prostacyclin as test $\sigma$ agents of vasoreactivity in severe precapillary pulmonary hypertension: predictive ability and consequences on haemodynamics and gas expredictive ability and consequences

14 Jones DK, Higgenbottam TW, Wallwork J. Treatment of primary pul- \& monary hypertension with intravenous epoprostenol (prostacyclin). monary hypertension with in

15 Mikhail G, Gibbs J, Richardson M, et al. An evaluation of nebulised prostacyclin in patients with primary and secondary pulmonary hypertension. Eur Heart F 1997:18:1499-504.

16 McCormack DG, Clarke B, Barnes CJ. Characterization of adenosine receptors in human pulmonary arteries. Am F Physiol 1989;256:H41-6.

17 Bush A, Busst CM, Clarke B, et al. Effect of infused adenosine on cardiac output and systemic resistance in normal subjects. Br F Clin Pharmacol 1989;27:665-8.

18 Nootens M, Schrader B, Kaufmann E, et al. Comparative acute effects of adenosine and prostacyclin in primary pulmonary hypertension. Chest 1995;107:54-7.

19 Murad F, Arnold W, Mittal CK, et al. Properties and regulation of guanylate cyclase and some proposed functions for cyclic GMP. Adv Cyclic Nucleotide Res 1979;11:175-204.

20 Ignarro LJ, Burke TM, Wood KS Association between cyclic GMP accumulation and acetylcholine-elicited relaxation of bovine intraaccumulation and acetylcholine-elicited relaxation of bovine

21 Robbins IM, Christman BW, Newman JH, et al. A survey of diagnostic practices and the use of epoprostenol in patients with pulmonary hypertension. Chest 1998;114:1269-75. .

\section{,}

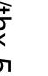


22 Farber HW, Karlinskz JB, Faling LJ. Fatal outcome following nifedipine for primary pulmonary hypertension. Chest 1983;83:708-9.

23 Aromatorio GJ, Uretsky BF, Reddy PS. Hypotension and sinus arrest with nifedipine in pulmonary hypertension. Chest 1985;87:265-7.

24 Weir EK, Rubin LJ, Ayres SM, et al. The acute administration of vasodilators in primary pulmonary hypertension: experience from the National Institutes of Health Registry on primary pulmonary hypertension. Am Rev Respir Dis 1989;140:1623-30.

25 Rich S, Kaufmann E, Levy PS. The effect of high doses of calcium channel blockers on survival in primary pulmonary hypertension. $N$ Engl 7 Med 1992;327:76-81.

26 Medical Research Council Working Party. Long term domiciliary oxygen therapy in chronic hypoxic cor pulmonale complicating chronic bronchitis and emphysema. Lancet 1981;681-6.

27 Nocturnal Oxygen Therapy Trial Group. Continuous or nocturnal oxygen therapy in hypoxaemic chronic obstructive lung disease. Ann Intern Med 1980;93:391-8.

28 Barst RJ, Rubin L, Long W, et al. A comparison of continuous intravenous epoprostenol (prostacyclin) with conventional therapy for
primary pulmonary hypertension. N Engl f Med 1996;334:296-301.
29 Torley HI, Madhok R, Cappell HA, et al. A double-blind, randomised, multicentre comparison of two doses of intravenous iloprost in the treatment of Raynaud's phenomenon secondary to connective tissue

30 Pasque MK, Kaiser LR, Dresler CM, et al. Single lung transplantation for pulmonary hypertension: technical aspects and immediate haemodynamic results. F Thorac Cardiovasc Surg 1992;103:475-81.

31 Higgenbottam TW, Spiegelhalter D, Scott JP. Prostacyclin (epoprostenol) and heart-lung transplantation as treatments for severe pulmonary hypertension. Br Heart f 1983;70:366-70.

32 Kerstein D, Levy PS, Hsu DT, et al. Blade balloon atrial septostomy in patients with severe primary pulmonary hypertension. Circulation 1995;91:2028-35.

33 Higgenbottam TW, Ward S, Brennan A, et al. Working group on accurate purchasing prostacyclin and iloprost in the treatment of pulmonary hypertension. Guidance for purchasers. 1997: 97/02 (abpulmonart).

34 Rolla G, Colagrande P, Brussino L, et al. Exhaled nitric oxide and pulmonary response to iloprost in systemic sclerosis with pulmonary hypertension. Lancet 1998;351:1491-2. 